\title{
REVOLUÇÃO TECNOLÓGICA, REDES SOCIAIS E DESAFIOS CONTEMPORÂNEOS PARA EFETIVAÇÃO DA CIBERDEMOCRACIA E DOS DIREITOS DO E-CIDADÃO: UMA PROPOSTA PARA REFERENDUM DE QUESTÕES POLÍTICAS IMPORTANTES
}

Marcelo Negri Soares ${ }^{1}$

Eudes Vitor Bezerra ${ }^{2}$

\section{RESUMO}

Este artigo, utilizando o método hipotético-dedutivo, sendo produto de estudos em nível de tese de doutoramento, analisa a revolução tecnológica, redes sociais e desafios contemporâneos para efetivação da ciberdemocracia e dos direitos do e-cidadão e, por fim, em sabendo da disponibilidade tecnológica, elabora uma proposta para referendum direto, não para todas as decisões, mas para questões políticas importantes na vida do cidadão brasileiro e que sejam compatíveis com esse modelo, que não colidam com direitos das minorias, com o nível de politização e educacional existente, bem como com matérias que exigem sigilo na tramitação, como no âmbito diplomático e dos direitos internacionais.

Palavras-Chave: Direito Constitucional; democracia; ciberdemocracia; e-cidadão; estado democrático de direito.

\section{TECHNOLOGICAL REVOLUTION, SOCIAL NETWORKS AND CONTEMPORARY CHALLENGES FOR THE EFFECTIVENESS OF CIBERDEMOCRACY AND E- CITIZEN'S RIGHTS: A PROPOSAL FOR REFERENDUM OF IMPORTANT POLITICAL ISSUES}

\begin{abstract}
This article, using the hypothetico-deductive method, being the product of studies at the doctoral thesis level, analyzes the technological revolution, social networks and contemporary challenges for cyberdemocracy and e-citizen rights, and finally, knowing Technological availability, elaborates a proposal for direct referendum, not for all decisions, but for important political issues in the life of the Brazilian citizen and that are compatible with this model, that do not collide with minority rights, with the level of political and educational existent, As well as with matters requiring secrecy in the process, such as diplomatic and international law.
\end{abstract}

Keywords: Constitutional Law; democracy; Cyberdemocracy; E-citizen; Democratic state.

\section{INTRODUÇÃO}

As redes sociais constituem forte tendência da contemporaneidade, pois, nos dias atuais as informações e manifestos ocorrem de forma praticamente instantânea, justamente pelo uso das redes sociais que, nesta contextualização desempenham um papel fundamental para o processo democrático. Mas por que não se utilizar a informatização e o modelo de acesso a

\footnotetext{
${ }^{1}$ Pós-Doutor em Direito pela UNINOVE/USP. Doutor em Direito pela Pontifícia Universidade Católica de São Paulo, PUC, São Paulo, (Brasil). Professor do Curso de Graduação em Direito da Universidade Federal do Rio de Janeiro (UFRJ) e do Programa de Mestrado em Ciências Jurídicas da UNICESUMAR - Maringá - Paraná.

${ }^{2}$ Doutor em Direito pela Pontifícia Universidade Católica de São Paulo, PUC, São Paulo, (Brasil). Coordenador do Curso de Graduação da Universidade Nove de Julho - São Paulo.
} 
redes sociais para se efetivar decisões no âmbito político, com a participação direta do povo brasileiro?

Naturalmente, são vários são os desafios para a efetivação dos direitos do e-cidadão. ${ }^{3}$

Na contemporaneidade importa frisar que a internet, já há algum tempo, deixou de ser uma simples rede de computadores, tornando-se um novo ecossistema social. Isso é tão presente em nossas vidas que, atualmente, não nos imaginamos sem sua presença.

A facilidade e a velocidade de comunicação desse meio tornaram o acesso à informação mais democrático, criando, assim, novas formas de relacionamentos, deram voz àqueles que, de certa forma, eram excluídos, permitindo a integração entre ideias e ideais, além de permitirem uma participação efetiva dos cidadãos na discussão do cenário político do país, expondo suas necessidades, inquietações e insatisfações por meio das redes sociais.

Nessa toada, no presente trabalho tecemos considerações sobre o e-cidadão como retrato do cidadão contemporâneo que vê nas redes sociais um forte instrumento de efetivação da democracia. Todavia, alguns desafios precisam ser superados, conforme adiante será esculpido. Nessa esteira também tem lugar a análise do papel das redes sociais no contexto de mudança. Expomos brevemente a revolução tecnológica, passando pela historicidade e os principais conceitos, e, principalmente o papel que as redes sociais vêm desempenhando na sociedade atual, especialmente no tocante às novas formas de manifestações, uma vez que, "nunca antes na história desse país", as redes sociais galgaram tantas transformações e impactaram diretamente nos meios políticos. Por fim, encaminha-se a ideia de ciberdemocracia, prós e contras na efetivação do e-cidadão.

\section{REDES SOCIAIS E REVOLUÇÃO TECNOLÓGICA}

Antes de adentramos às redes sociais, propriamente ditas, é importante falarmos sobre o marco que revolucionou o mundo contemporâneo, ou seja, a revolução tecnológica. Antes ainda, e por oportuno, importa lembrar que, antes mesmo de falar em tecnologia, tivemos vários outros aspectos de suma importância para o desenvolvimento civilizatório da humanidade, dentre eles, salientamos o processo de comunicação, conforme mencionado no item 1.1.1 (Manifestação: Da comunicação à lógica), que foi condição primeira para o desenvolvimento da raça humana.

Tal assertiva se justifica tendo em vista que, por meio da comunicação, nós humanos conseguimos expressar nossos sentimentos, nos relacionarmos, recebermos e transmitirmos informações, compartilharmos conhecimentos, bem como manifestarmos nossas ideias.

Na infância dos povos, a comunicação era extremamente precária, sendo que a raça humana se comunicava por meio de sinais, gestos, expressões faciais e outros. A fala foi o primeiro grande avanço do processo de comunicação, sendo certo que o uso da linguagem

\footnotetext{
${ }^{3}$ No presente trabalho, consideramos e-cidadão como sendo um cidadão contemporâneo, preocupado com as questões políticas e sociais, interligado com vários outros cidadãos por meio da rede mundial de computadores e que utiliza as redes sociais para expor seu ponto de vista, realizar e organizar manifestos, sem, contudo, abandonar as praças públicas.
} 


\section{REVOLUÇÃO TECNOLÓGICA, REDES SOCIAIS E DESAFIOS \\ CONTEMPORÂNEOS PARA EFETIVAÇÃO DA CIBERDEMOCRACIA E DOS \\ DIREITOS DO E-CIDADÃO: UMA PROPOSTA PARA REFERENDUM DE \\ QUESTÕES POLÍTICAS IMPORTANTES}

favoreceu os grupos que a desenvolveram no processo de seleção e conquistas culturais, responsáveis pela própria sobrevivência ${ }^{4}$.

Mas foi no Século XX, por volta da década de 70, que se deu o grande marco da revolução tecnológica. Vejamos algumas datas importantes para entendermos a evolução tecnológica ${ }^{5}$ : 1965 - Lançados os primeiros satélites de comunicação. Inaugurada uma nova era na transmissão de dados eletrônicos.

1972 - Os discos laser são lançados revolucionando a indústria fonográfica.

1977 - Lançado nos Estados Unidos o primeiro telefone celular.

1990 - Lançamento do primeiro navegador de hipertexto para a Internet. Somente no ano seguinte o programa foi disponibilizado.

1999 - A Internet cresce no mundo todo em velocidade impressionante. Os arquivos de MP3 começam a ser usados e transmitidos pelas ondas da Internet.

2007 - A Apple lança seu primeiro Iphone. Tem início a Era dos Smartphones (híbrido de telefone celular e computador pessoal).

Todos esses acontecimentos possibilitaram uma amplitude nos meios de informação, sendo que a revolução tecnológica excedeu limites antes inimagináveis no que tange à democratização do processo de comunicação.

Aníbal Sierralta Ríos ${ }^{6}$ argumenta:

Para o direito e a democracia, a forma e a dimensão dos meios de informação são significativas não somente por sua estrutura empresarial, mas também pelos diferentes e diversos interesses que defendem e pelas formas como podem interferir na sociedade para impor esses interesses, afetando, assim, a cultura dos povos e também manipulando a história.

De fato, a revolução tecnológica mudou expressivamente os padrões culturais relacionados à comunicação, mudando, também, a forma como as pessoas manifestam suas insatisfações, pois voltam-se contra o injusto, insurgem-se com a norma arbitraria.

Desse modo, o processo de comunicação que no embrião da civilização era adstrito aos signos, sons, alcançou o advento da palavra escrita, desenvolvendo-se, mais ainda, com a chegada da tipografia móvel, prosseguiu para a comunicação de massa (jornais, rádios, televisão) e progrediu, como nunca, com a revolução tecnológica, que podemos considerar o marco inicial para o surgimento, posterior, das redes sociais, e, por consequência lógica, foi o marco, também, para as novas formas de manifestações e criação do e-cidadão.

\footnotetext{
${ }^{4}$ LIMA, Sandra Lúcia Lopes. História da comunicação. São Paulo: Ebart, 1989. p. 9.

5 SUA PESQUISA PONTO COM. Tecnologia e história da tecnologia. Disponível em: <http:/ /www.suapesquisa.com/tecnologia/>. Acesso em: 11 mar. 2016.

${ }^{6}$ RIOS, Aníbal Sierralta. A revolução tecnológica dos meios de comunicação e os desafios do direito e da democracia. Revista Meritum, v. 7, n. 1, p. 305-353, jan./jun. 2012.
} 


\section{CONCEITOS}

O convívio em sociedade fez com que o homem evoluísse em relação à comunicação social, fato esse primordial, porquanto o indivíduo necessitava realizar relações de interação com outros indivíduos. Manifestamente, com o avanço da tecnologia, toda comunicação com um grupo da sociedade foi facilitada, conforme acima explicitado.

Mais, as pessoas desenvolvem a capacidade de se comunicar e interagir umas com outras, toda vez que ocorre o avanço tecnológico, hoje, por exemplo, já não é casual o uso de cartas, telegramas e ligações via o sistema de telefonia. A primeira ligação ou o primeiro "alô", via telefone celular ${ }^{7}$, era sonho de várias pessoas, já nos dias atuais diz o brocardo popular que: "Em terra de WhatsApp ligação é prova de amor" 8 , ou seja, os avanços tecnológicos transformam a forma como nos relacionamos, como nos comunicamos e também como nos manifestamos e participamos do processo democrático na era digital.

Tanto é verdade que, com o advento da internet, houve reconhecida aceleração no processo de comunicação, de modo que novas ferramentas de comunicação sempre apresentam grande destaque e crescimento na rede mundial de computadores ${ }^{9}$, desde os primeiros meios, como o próprio correio eletrônico (e-mail). Ademais, com o advento das redes sociais, essas relações entre diferentes pessoas tornaram-se mais comuns.

Impende ressaltar que existem outros instrumentos que podem ser confundidos com redes sociais, por tais motivos, as pesquisadoras norte-americanas Danahet Boyde e Nicole Ellison definem as Redes Sociais (Social Network Sites), como:

(...) serviços baseados na web que permitem ao indivíduo construir um perfil público ou semi-público dentro de um sistema pré-formatado, onde se desenvolve uma lista de conexões com outros usuários, com os quais se compartilham informações e onde é possível ver e percorrer as listas de conexões desses outros usuários dentro do sistema. (Tradução livre). ${ }^{910}$

\footnotetext{
${ }^{7}$ A primeira cidade brasileira a contar com telefonia móvel celular foi o Rio de Janeiro, em 1990. Posteriormente, em 1991, o sistema foi implantado também em Brasília e, depois disso, em Campo Grande, Belo Horizonte, Goiânia e São Paulo. Em novembro de 1993, a Telesp Celular lançou o primeiro sistema digital de telefonia celular e em 1997, foi inaugurada em Brasília a primeira operadora da banda B (concorrentes privadas ao monopólio estatal que existia até então): a Americel. A entrada de operadoras na banda B foi o pontapé inicial na abertura do mercado de telefonia móvel, possibilitada pela Lei Mínima (Lei no 9.295, de 16 de julho de 1996).

Disponível em: <GUIA DO CELULAR. História do celular no Brasil. Disponível em: <http://www.guiadocelular.com/2011/10/ historia-do-telefone-celular-no-brasil.html>. Acesso em 01 de set.de 2016.

${ }^{8}$ Realmente não há dúvidas de que a internet e a tecnologia melhoraram as nossas vidas. Mas elas também pioraram. Quanto mais utilizamos os avanços da informática e nos habituamos ao processamento rápido da velocidade, mais nos robotizamos. Tornamo-nos as próprias máquinas. E os relacionamentos humanos são os que mais têm sofrido com essa transformação, principalmente as relações amorosas quando estão em seu início.

BEDONE, Rebeca. Em terra de whatsapp ligação é prova de amor. Disponível em: <http://www.revistabula.com/5323-em-terra-de-whatsapp-ligacao-e-prova-de-amor/>. Acesso em: 11 mar. 2016. ${ }^{9}$ CARVALHO NETO, Frederico da Costa. Novas Ferramentas e Privacidade. Florianópolis: FUNJAB, 2013. p. 233-249.

${ }_{9}^{9}$ BOYD, Danahet; ELLISON, Nicole. Social network sites: Definition, history, and scholarship. Califórnia,

10 . Disponível em: <http://jcmc.indiana.edu/vol13/issue1/boyd.ellison.html>. Acesso em: 04 jun. 2013. "webbased services that allow individuals to construct a public or semi-public profile within a bounded system, articulate a list of other users with whom they share a connection, and view and traverse their list of connections and those made by others within the system".
} 


\title{
REVOLUÇÃO TECNOLÓGICA, REDES SOCIAIS E DESAFIOS CONTEMPORÂNEOS PARA EFETIVAÇÃO DA CIBERDEMOCRACIA E DOS DIREITOS DO E-CIDADÃO: UMA PROPOSTA PARA REFERENDUM DE QUESTÕES POLÍTICAS IMPORTANTES
}

As denominadas redes sociais digitais motivam uma interação social para dentro do ambiente virtual. Nesse sentido, podemos defini-las como um conjunto de sistemas digitais, utilizados por indivíduos de maneira não centralizada, o que permite uma significante interação interpessoal, já que compartilham ideias, divergências, fotos, vídeos, dentre outros conteúdos.

Mas, existem pesquisadores que realizam uma explicação mais extensiva do que seriam "redes sociais", pois, para estes, a definição seria apenas para qualquer "site" que permite partilhar dados e informações, sendo estas de caráter geral ou específico, das mais diversas formas (textos, arquivos, imagens fotos, vídeos). Nesse sentido, segundo Danilo Doneda:

\begin{abstract}
Existem ainda as redes sociais denominadas como impróprias, que seriam aquelas que funcionam como um apêndice de outro serviço ou ferramenta, gravitando e existindo em função deste. Estas redes impróprias podem oferecer um conjunto parcial das ferramentas típicas de interação encontradas nas redes sociais próprias, e podem ser mencionados como exemplos as redes sociais presentes em sites de comércio eletrônico (tais como o da Amazon.com, eBay ou o Mercado Livre) ou em sites que têm como objetivo primordial o intercâmbio de conteúdo e não propriamente a interação social mas que também cultivam suas próprias comunidades de usuários (tais como o Slideshareou o próprio YouTube). ${ }^{11}$
\end{abstract}

Ante essa assertiva, resta evidente que atualmente houve uma transformação, com isso, deve-se atentar ao fato de que as redes sociais passaram a ser também uma plataforma de utilização de aplicativos (jogos, utilitários) e de comércio eletrônico (como é caso do YouTube, do Facebook), além da possibilidade de criação de páginas institucionais e/ou pessoais.

Por tais causas, seria mais acertado conceituar as redes sociais como espaços virtuais pré-estabelecidos que propiciam a interação de indivíduos e instituições, por meio da composição de listas de relacionamento e o preenchimento de informações nos perfis pessoais e páginas institucionais, bem como por meio de aplicativos de informática.

$\mathrm{Na}$ grande maioria das vezes, a utilização das redes ocorre de forma gratuita, todavia, a maioria das empresas oferecem seus préstimos em troca dos dados, e esses dados são comercializados aos mais diversos setores da economia, ou seja, os usuários inserem seus dados que são automaticamente processados para, posteriormente, oferecerem publicidade personalizada e marketing de relacionamento, destinados a pequenos produtores de programas de computador ou artesanato, até bancos e montadoras de automóveis.

São as redes sociais os meios cibernéticos pré-estabelecidos que propiciam a interação interpessoal, nas quais as pessoas inserem seus dados pessoais, compartilham seus sonhos, frustações, realizações com outras pessoas conhecidas ou não.

Do exposto, podemos afirmar que as redes sociais são um instrumento de proliferação da comunicação que atingem de forma instantânea pessoas em todos os lugares do mundo. São, também, um instrumento de participação popular nas decisões dos governantes, tendo em vista

\footnotetext{
${ }^{11}$ DONEDA, Danilo. Reflexões sobre proteção de dados pessoais em redes sociais. Revista Internacional de Protección de Datos Personales. n. 1. Dezembro 2012. Disponível em: <http://habeasdatacolombia.uniandes.edu.co/wp-content/uploads/10_Danilo-Doneda_FINAL.pdf >. Acesso em: 5 fev. 2014.
} 
que as manifestações se proliferam de forma imediata e o alcance é sem precedentes, fazendo com que alguns governantes revejam seus posicionamentos.

\section{EVOLUÇÃO HISTÓRICA DAS REDES SOCIAIS}

No século XIX, mais precisamente em 1971 aconteceu um passo formidável, ou seja, o envio do primeiro "e-mail”. Sete anos depois ocorreu a criação do Bulletin Board System (BBS), tecnologia essa que usava linhas telefônicas e um modem para transmitir os dados, oportuno mencionar que o sistema foi criado por dois entusiastas de Chicago, para convidar seus amigos para eventos e realizar anúncios pessoais.

Passados outros sete anos, outro fato marcante acerca da evolução histórica das redes sociais adveio, ou seja, em 1985 a America Online (AOL), passou a fornecer ferramentas para que as pessoas construíssem perfis virtuais nos quais podiam descrever a si mesmas e criar comunidades para troca de informações e discussões sobre os mais variados assuntos. Anos mais tarde (mais precisamente 1997), a empresa implementou um sistema de mensagens instantâneas, o pioneiro entre os chats e a inspiração dos "menssengers" utilizados atualmente. ${ }^{12}$

A “internet", na virada do século, anos 2000, teve um aumento significativo de presença na casa das pessoas e no trabalho. Com isso, as redes sociais alavancaram uma imensa massa de usuários ${ }^{13}$ e a partir desse período uma infinidade de serviços foram surgindo, como o Fotolog, que consistia em publicações baseadas em fotografias acompanhadas de ideias, sentimentos.

O denominado Friendster é considerado como o primeiro serviço a ganhar o status de "rede social". Suas funções admitiam que as amizades do mundo real fossem conduzidas para o espaço virtual. Esse meio de comunicação e socialização atingiu 3 milhões de adeptos em apenas três meses - o que significava que 1 a cada 126 internautas da época possuía uma conta nele. $^{14}$

Em ato posterior, as redes sociais passaram a ser apreciadas de tal forma pelos usuários, que se volveram como efetivas máquinas de captação de dinheiro, o que impulsionou a criação, em 2004 do Orkut e Facebook.

Durante anos, o Orkut foi a rede social de propriedade da Google, mais usada pelos internautas brasileiros, até perder sua posição em dezembro de 2011 para o Facebook, criação de Mark Zuckerberg.

Em que pese sua criação, data de 2004, criado dentro do campus da Universidade de Harvard, o Facebook só atingiu a grande massa de usuários no ano de 2006. De lá para cá, a

\footnotetext{
${ }^{12}$ TECMUNDO. A história das redes sociais como tudo começou. Disponível em: $<$ http://www.tecmundo.com.br/redes-sociais/33036-a- historia-das-redes-sociais-como-tudo-comecou. htm> Acesso em: 10 abr. 2013.

${ }^{13}$ CARVALHO NETO, Frederico da Costa. Novas Ferramentas e Privacidade. Conpedi/Uninove. Florianópolis: FUNJAB. 2013. p. 233-249.

${ }^{14}$ TECMUNDO. A história das redes sociais como tudo começou. Disponível em: <http://www.tecmundo.com.br/redes-sociais/33036-a-historia-das-redes-sociais-como-tudo-comecou.htm>. Acesso em: 10 abr. 2013.
} 


\section{REVOLUÇÃO TECNOLÓGICA, REDES SOCIAIS E DESAFIOS CONTEMPORÂNEOS PARA EFETIVAÇÃO DA CIBERDEMOCRACIA E DOS DIREITOS DO E-CIDADÃO: UMA PROPOSTA PARA REFERENDUM DE QUESTÕES POLÍTICAS IMPORTANTES}

rede social é sinônimo de sucesso e crescimento, superando a incrível marca de 908 milhões de pessoas cadastradas e a marca está avaliada em US\$ 104 bilhões. ${ }^{15}$

Não obstante, temos, também, outra recente rede social a entrar nessa complicada contenda, é o Google+, um dos mais novos serviços da enorme e mundialmente reconhecida Google. Difundido oficialmente em 2011, esse serviço tem por volta de 400 milhões de inscritos (somente $25 \%$ deles estão ativos). Conquanto ainda esteja muito longe de assustar o líder do segmento, a Google não tem poupado investimentos e esforços para que o seu produto cresça. Contudo, por enquanto, ele ainda não vingou e o volume de informações compartilhadas pelo Google+ ainda é relativamente baixo.

Em contemporânea pesquisa, publicada pela The Social Habbit, nos Estados Unidos da América, dentre os norte-americanos entrevistados, que na época utilizavam alguma plataforma de mídias sociais, $18 \%$ possuem um perfil no Instagram, 94\% no Facebook e 47\% no Twitter.

Nessa toada, e para demostrar que o acesso a essas redes sociais é mais constante que outras formas de socialização do cidadão, daqueles que possuíam um perfil do Instagram $61 \%$ estiveram ativos pelo menos uma vez por dia, um nível de adoção apenas ultrapassado pelo Facebook (84\%). Em comparação, o Twitter está em 55\%, Google Plus 44\% e o Pinterest com $52 \% .16$

Ante o exposto, percebemos cada vez mais o surgimento dessas novas redes sociais e deparamos com a necessidade de realizarmos sua melhor compreensão sociológica e jurídica para se conseguir regular tais relações virtuais.

\section{LIBERDADE DE MANIFESTAÇÃO NA "ERA DA INFORMÁTICA"}

Com o surgimento da internet, é possível afirmar que a pulverização de dados verdadeiros ou falsos sobre um determinado assunto ou pessoa, se tornou muito mais fácil que outrora, permitindo-se a construção de uma biografia que pode distorcer ou não a realidade dos fatos e a identidade das pessoas.

Sabemos que na atual era da cibernética, a manifestação de pensamento, previsto no art. $5^{\circ}$, inciso IV da Constituição Federal de 1988, ganhou proporções inimagináveis, frente a quase completa eliminação de barreiras para a disseminação da liberdade de manifestação.

Salientamos que os mecanismos de comunicação cibernéticos são considerados como avanço da ciência e da tecnologia ${ }^{17}$, assim, reconhece-se a necessária reengenharia do tradicional conceito de manifestação nos dias atuais.

Todavia, não podemos esquecer que a proliferação do direito de manifestação por meio da internet não jogou por terra o outro preceito constitucional que vem aliado ao direito de

15 TECMUNDO. A história das redes sociais como tudo começou. Disponível em: <http:// www.tecmundo.com.br/redes-sociais/33036-a-historia-das-redes-sociais-como-tudo-comecou.htm>. Acesso em: 10 abr. 2013.

${ }^{16}$ BUSINESS SOLUTION INTERNATIONAL. Dados recentes sobre a ascensão do "Instagram". Disponível em: <http://www.bsi-brasil.com/blog/dados-sobre-ascensao-do-instagram-102101218/>. Acesso em: 03 jul. 2015.

${ }^{17}$ MAIN, Lucimara Aparecida; MORO, Maitê. Reputação da organização: gerenciamento de crise da imagem, como forma de garantir a função social e sustentabilidade financeira da empresa. Florianópolis: FUNJAB. 2014. p. 493-516. 
manifestação, ou seja, continua vedada a manifestação às escuras, em outras palavras, é garantido o direito de manifestação, mais vedado o anonimato.

O cidadão ou e-cidadão pode, caso queira, fazer das redes sociais sua forma de "palanque virtual" de manifestação contra aquela norma, ato ou ordem que considere injusto; no entanto, não pode se esconder atrás da cibernética e falar o que bem pensa sem o condão da responsabilização, pois somos responsáveis pelos nossos atos dentro ou fora do mundo virtual.

O que temos, efetivamente, é uma ausência de regulamentação, por parte do Estado que, por sua vez, deve criar mecanismos de policiamento virtual, similar ao que ocorre no "mundo real", de modo que seja possível identificar e punir o usuário que pratica delitos no ambiente virtual, ou seja, usuários que vão além do exercício do direito de manifestar.

Como mencionamos anteriormente, as empresas que administram as redes sociais, buscam o lucro, ao passo que deve o Estado, também, criar mecanismos de policiamento virtual e de responsabilização civil destinada às pessoas jurídicas.

Nessa esteira de pensamento, a criação de mecanismos estatais de fiscalização e punição tanto para o indivíduo, quanto para as empresas que administram as redes sociais, nos parece o melhor caminho para a efetivação da democracia e o exercício da livre manifestação, sem, contudo, prejudicar terceiros.

\section{GERAÇÃO Z: AS REDES SOCIAIS COMO NOVA FORMA DE MANIFESTAÇÃO}

As redes sociais é de longe o melhor mecanismo de comunicação criado pelo homem, não desprezamos a importância dos mecanismos anteriores, (telégrafo, rádio, TV, telefones); contudo, podemos observar uma democratização por meio das redes sociais.

Uma grande evolução, advinda da Geração Z, foi a transformação na forma como se convocam e se realizam as manifestações, fato esse que restou evidente pelas últimas manifestações, políticas ou não, que ocorreram no Brasil.

Imaginava-se que a Geração Z ficaria atrás de um smartphone, atrás de um computador, notebook ou tablet, que seria uma geração de nerds virtuais, desapegados do mundo alémparedes dos seus quartos, contudo introduziram, via redes sociais, uma nova visão sobre como as pessoas no século XXI podem mobilizar outras. Essa mobilização ocorre via canais disponíveis na internet, por exemplo, YouTube, e principalmente pelas redes sociais, sendo que no Brasil Facebook, Twitter, Instagram têm se destacado e impulsionaram as últimas manifestações.

Via de regra, os jovens utilizavam as redes sociais para mobilização, convocação e realização das manifestações nas vias públicas, principalmente aquelas de maior circulação, como ocorreu em diversas oportunidades na Avenida Paulista (considerada o centro financeiro do país), na Cidade São Paulo/SP.

Nessa toada, tem-se que a Geração Z, via redes sociais, inflaram as manifestações, uma vez que atingiram números antes nunca vistos em atos populares/públicos no Brasil. Todavia, nem todas as manifestações propagadas pelas redes sociais são de cunho político, uma vez que várias outras questões, também, foram suscitadas nas redes sociais e motivaram manifestos públicos, que, como ocorreram, a título de exemplificação veremos mais adiante, não eram de cunho político, mas social. 


\title{
6. DESAFIOS CONTEMPORÂNEOS PARA EFETIVAÇÃO DOS DIREITOS DO ECIDADÃO
}

Com o advento da internet e das redes sociais, os fatores geográficos e sociais deixaram de ser limitadores para o agrupamento e a discussão política.

Por intermédio da internet, as pessoas conseguem facilmente se agrupar por interesses comuns, sejam eles ideológicos, políticos ou sociais, mesmo estando geograficamente distantes ou sendo de diferentes grupos ou classes sociais. Essas novas tecnologias da informação estão mudando, inclusive, as formas de manifestações políticas da sociedade, fato já mencionado anteriormente, visto que as últimas manifestações políticas ocorridas no Brasil foram principalmente convocadas através das redes sociais.

Destarte, percebemos a formação, a transformação do cidadão para o e-cidadão, que se deu pela democratização do acesso à rede mundial de computadores, com marco inicial da revolução tecnológica.

Luciana Cristina de Souza aduz:

\begin{abstract}
Defende-se a hipótese de que o exercício da capacidade da resiliência (e sua aplicação como princípio basilar do reconhecimento democrático) tanto enseja uma comunicabilidade de melhor qualidade entre a autoridade pública e a Sociedade Civil, quanto propicia a horizontalização das tomadas de decisão de interesse dos cidadãos. Após delinear o novo perfil da democracia no Brasil, explica-se o que é e como se aplica o princípio da resiliência estatal, considerando sua importante função para o ordenamento jurídico na atualidade tomando-se como exemplo a chamada edemocracia, ou democracia digital, meio de comunicação que tem crescido e se destacado na última década e pelo qual foram articuladas e convocadas muitas das recentes manifestações nacionais. ${ }^{18}$
\end{abstract}

Através da troca de informações entre os relacionamentos virtuais, o e-cidadão foi se criando e, hoje, desponta como uma realidade, contudo, as redes sociais, não retiraram do ecidadão anseio pelas praças públicas, muito pelo contrário apenas fomentou uma melhor organização e proliferação das convocações para os manifestos em ruas, avenidas, parques, praças públicas.

Para Manuel Castells, o desenvolvimento sem internet na era da participação seria o equivalente à industrialização sem eletricidade na era industrial. Sustenta, ainda, que, sem uma economia e gestão baseadas na internet, qualquer país tem pouca chance de gerar os recursos necessários para cobrir suas necessidades de desenvolvimento num terreno sustentável, sob todos os aspectos. ${ }^{19}$

Para melhor entendemos a figura do e-cidadão, temos de averiguar a pirâmide criada por João Carlos Caribé ${ }^{20}$, baseada na Hierarquia das necessidades de Maslow, que pode ser utilizada ${ }^{18}$ SOUZA Luciana Cristina de. Análise crítica da legitimidade do estado a partir da aplicação do princípio
da resiliência. Direito, governança e novas tecnologias. CONPEDI/ UFMG/FUMEC/Dom Helder Câmara;
$\begin{array}{llll}\text { Florianópolis: } & \text { CONPEDI, } & 2015 . & \text { Disponível }\end{array}$ 
para descrever as necessidades que devemos conhecer no decorrer do processo de inclusão digital bem como a construção do e-cidadão.

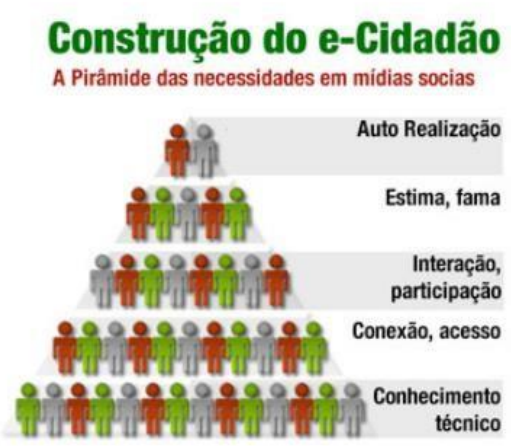

Fonte: Caribé (2011)

O autor define cada um dos níveis, conforme abaixo exposto:

Conhecimento tecnológico - conhecimento técnico mínimo necessário para permitir o usuário utilizar um dispositivo computacional.

Conexão, acesso - Esta segunda etapa está dentro dos objetivos de infraestrutura e acesso.

Interação, participação - É o momento em que o usuário começa a interagir em mídias sociais, é o momento das descobertas que em geral são feitas com pares próximos laços fortes.

<http://www.conpedi.org.br/publicacoes/66fs1345/81s48682/0cO30v9hDfn0KKv1.pdf>. Acesso em: 11 ago. 2016.

19 CASTELlS, Manuel; CARDOSO, Gustavo (Orgs.). A sociedade em rede: do conhecimento à ação política. Belém: Imprensa Nacional, 2005. p. 71.

20 CARIBÉ, J. C. Classes Populares. In: BRAMBILLA, Ana (org.). Para entender as mídias sociais. Ebook, 2011. Disponível em: http://designices.com/wp-content/uploads/2011/04/paraentenderas midiassociais.pdf >. Acesso em: 18 ago. 2016.

Estima, reconhecimento - $\mathrm{O}$ usuário já transita com facilidade no novo espaço e tornou-se de fato um integrante, um prosumer que produz e compartilha em busca de estima e reconhecimento.

Autorrealização - $\mathrm{O}$ usuário conseguiu produzir relevância junto aos seus pares, e dentro do seu nicho de atuação, é um ciber celebridade, conquistou respeito e admiração. ${ }^{19}$

Dessa forma, para que os objetivos da inclusão social, bem como a efetivação do ecidadão sejam atingidos, faz-se necessário muito mais do que o simples acesso à internet ou o conhecimento técnico sobre ela, é imprescindível entendermos como as relações entre os atores desse ecossistema social ocorrem, ou seja, entender como se dá a relação entre os incluídos e a rede.

Fica evidente que o acesso à cibernética é fator crucial para que a exclusão digital seja combatida e assim a participação política do e-cidadão seja plena.

Do exposto, podemos concluir que o e-cidadão é o indivíduo contemporâneo preocupado com as questões políticas e sociais que está interligado com vários outros indivíduos

${ }^{19}$ CARIBÉ, J. C. Classes Populares. In: BRAMBILLA, Ana (org.). Para entender as mídias sociais. E-book, 2011. Disponível em: http://designices.com/wp-content/uploads/2011/04/paraentenderas midiassociais.pdf>. Acesso em: 18 ago. 2016. 


\title{
REVOLUÇÃO TECNOLÓGICA, REDES SOCIAIS E DESAFIOS \\ CONTEMPORÂNEOS PARA EFETIVAÇÃO DA CIBERDEMOCRACIA E DOS \\ DIREITOS DO E-CIDADÃO: UMA PROPOSTA PARA REFERENDUM DE \\ QUESTÕES POLÍTICAS IMPORTANTES
}

por meio da rede mundial de computadores e que utiliza as redes sociais para expor seu ponto de vista, realizar e organizar manifestos, sem, contudo, abandonar as praças públicas.

\section{CONVOCAÇÕES DE MANIFESTAÇÕES PELAS REDES SOCIAIS: PARTICIPAÇÃO POLÍTICA COMO EXPRESSÃO DA DEMOCRACIA OU DESORDEM?}

A forma como o acesso à cibernética impactou nossas vidas é sem precedentes. A ponto de podemos afirmar que não conseguimos mais viver sem o uso das novas tecnologias, eis que foram vários os benefícios em todas as esferas da vida humana.

Um dos principais benefícios, no que tange a relações interpessoais, foi as redes sociais, que têm o condão de aproximar a pessoas, de viabilizar o dialogo, de transmitir informações de forma instantânea num contexto transnacional, ou seja, as redes sociais transpuseram barreiras antes inimagináveis, quer pela distância, quer pelo idioma.

Várias são as redes sociais disponíveis aos indivíduos no ciberespaço, por exemplo, o

Facebook e o Twitter que, junto com as demais redes sociais, mudaram a forma como nos comunicamos e como ocorrem as mobilizações sociais.

Se antes a mobilização social levava dias, semanas ou até meses, com o advento das redes sociais, as mobilizações sociais acontecem em fração de segundo, tendo em vista a instantaneidade da comunicação, assim, as redes sociais são grandes facilitadoras para a viabilidade de sincronização de pessoas desconhecidas, ou não, mas em diferentes locais.

\begin{abstract}
As novas mídias sociais como Facebook e Twitter mudaram o uso da expressão 'mobilização social".

Essas mídias são grandes facilitadoras uma vez que sincronizam diferentes grupos espalhados num mesmo país ou no mundo, facilitam a coordenação das ações e ajudam a documentar o que está acontecendo. E por mais que questione o grau de ativismo destas redes estudos já apontam que as mídias sociais ao contrário de uma visão comum, estão expondo mais pessoas a questões humanitárias e sociais.

As causas políticas talvez sejam a melhor forma de exemplificar os sucessos e os desafios que essas mídias sociais enfrentam e vão enfrentar. Os recentes levantes no mundo árabe foram marcados por mobilização que, no mínimo, foram facilitadas e antecipadas pelo uso das mídias sociais. Se num primeiro olhar, se vê o sucesso para entender as Mídias Sociais, o uso da internet, nas revoltas do Egito e da Tunísia, por outros, sabe-se também que a onda verde invadiu o twitter e o facebook durante a luta do povo Iraniano contra o governo autoritário que se virou contra eles, a partir do momento em que a revolta falhou e estas mesmas mídias servem hoje como banco de dados para a busca e a apreensão de pessoas por esse regime. Mais recentemente, o governo da Líbia, assim que percebeu a mobilização online, bloqueou a internet no país. Mas isto também não é uma novidade histórica e nem a primeira vez que regimes autoritários se apoderam dos meios de comunicação para manter seu poder. ${ }^{20}$
\end{abstract}

\footnotetext{
${ }^{20}$ BARRETO, Fernando. Mobilização Social. In: BRAMBILLA, Ana (org.). Para entender as mídias sociais. Ebook, 2011. Disponível em: http://designices.com/wp-content/uploads/2011/04/paraentenderas midiassociais.pdf>. Acesso em: 18 ago. 2016.
} 
Temos, então, que as redes sociais ocupam papel central nas recentes transformações que estamos presenciando, em especial, em relação aos rumos da política, mas também, em todos os demais aspectos da vida social.

As tecnologias digitais ocupam um papel central nas profundas mudanças experimentadas em todos os aspectos da vida social. A natureza, motivos, prováveis e possíveis desdobramentos dessas alterações, por sua vez, são extremamente complexos, e a velocidade do processo tem sido estonteante. $\mathrm{O}$ advento da Internet trouxe diversas mudanças para a sociedade. ${ }^{21}$

Destarte, as redes sociais digitais podem ser utilizadas para vários fins, como, por exemplo, para convocação de show, para um jogo, bem como para as pessoas protestarem por um país melhor:

Com as redes sociais digitais, embora possam ser usadas para fins diversos - para convocação de um show de um artista qualquer, para assistir a um jogo etc., para protestar por um país mais justo - como ocorreu no país, vão se criando identidades que extrapolam o tempo e o território, pois as ações por elas desencadeadas extrapolam as fronteiras, fazendo-as cada vez mais fluidas no âmbito das redes virtuais, embora tenham esse caráter indiferente, ou seja, podendo ser usadas para fins diversos. $^{22}$

A partir das jornadas de junho de 2013, além do surgimento do e-cidadão, surgiram, também, os Black Bloc, ambos já mencionados anteriormente. Outro fenômeno também aconteceu com as manifestações vias redes sociais (no próprio ciberespaço ou organizadas nele), trata-se do uso dos partidos políticos e dos próprios políticos, seja qual for a sigla, fazem das redes sociais para se beneficiarem, por intermédio de falácias com promessas, engodos, maiormente com o "juramento" da efetivação da democracia.

Dessa feita, a utilização das redes sociais, seja para manifestar ou para realizar convocações de manifestações, como forma de participação política como, e, por consequente, como expressão da democracia, trouxe benefícios que sobrepõe os pontos negativos, todavia esses também existem:

\footnotetext{
Os pontos negativos das convocações para manifestação pelas redes sociais são: 1Um fato negativo que está acontecendo de maneira cada vez mais intensa com as manifestações que ocorreram no país no período citado, diz respeito às práticas de engodo dos diversos partidos políticos que estão ludibriando, com suas ideologias, a sociedade. (...)

2- Outra característica é que os seus participantes nem sempre são membros de uma mesma cultura. ${ }^{25}$
}

\footnotetext{
${ }^{21}$ RECUERO, R. Redes Sociais na Internet. Porto Alegre: Sulina, 2009. Disponível em: <http://www.ichca.ufal.br/graduacao/biblioteconomia/v1/recuero.pdf>. Acesso em: 18 ago. 2016. p. 24.

22 SANTOS, José Erimar dos.; SANTOS, Valmaria Lemos da Costa. Geografia dos protestos e meio comunicacional: redes sociais digitais e manifestações populares. Revista Movimentos Sociais e Dinâmicas Espaciais. Recife, v. 2, n. 2, 2013. Disponível em: <http://www.revista.ufpe. br/revistamseu/index.php/ revista/article/viewFile/50/92>. Acesso em: 18 ago. 2016. ${ }^{25}$ Idem (SANTOS, 2013).
} 


\title{
REVOLUÇÃO TECNOLÓGICA, REDES SOCIAIS E DESAFIOS CONTEMPORÂNEOS PARA EFETIVAÇÃO DA CIBERDEMOCRACIA E DOS DIREITOS DO E-CIDADÃO: UMA PROPOSTA PARA REFERENDUM DE QUESTÕES POLÍTICAS IMPORTANTES
}

Em que pese a existência de pontos negativos, não podemos negar que foi graças às redes sociais digitais mencionadas, que surgiu esses novos instrumentos de comunicação, por meio dos quais as massas ergueram-se contra as iniquidades civis.

As convocações por esses meios cibernéticos, tais como Facebook e Twitter que transformaram a participação política como, e, por consequente, democracia, principalmente pelo e-cidadão e por meio da ciberdemocracia, já que milhares de manifestantes foram às ruas por meio de convocações, ocorridas via redes sociais, aspirando, assim, novos espaços de efetividade da democracia e da cidadania, uma vez que a cibernética permitiu transformações quanto à configuração de organização social, sendo as redes sociais a arma das mobilizações ocorridas no país.

Como as redes sociais não fazem distinções, uma vez que o acesso é irrestrito, podemos observar que os Black Blocs também fizeram das redes sociais seus instrumentos de aparelhamento para suas táticas:

\begin{abstract}
À medida que a violência do Estado era experimentada pelo corpo, captada por câmeras e smartphones, e denunciada nas redes sociais, cada vez mais manifestantes adotaram posições políticas radicais e aderiam à performance e indumentária peculiares à tática Black Bloc. Os pequenos danos ao patrimônio que teriam justificado a violência policial do início de junho multiplicaram-se à medida que um número crescente de jovens passava a vestir máscaras e engarjar-se em gestos iconoclastas de depredação de agências bancárias, prédios públicos, ônibus, viaturas e demais ícones do poder político e econômico. ${ }^{23}$
\end{abstract}

Ainda sobre o aparelhamento pelos Black Blocs via redes sociais, temos que eles se organizavam/organizam principalmente via Facebook, todavia, utilizam outras redes, também, pois através de marcação de protestos, posts que reforçam a identidade BB:

Embora não seja um fenômeno novo, muito menos de raiz nacional, a atuação do Black Bloc no Brasil, até por não haver sites ou organização institucional formal, dáse em boa parte via articulação no Facebook, através de marcação de protestos, posts que reforçam a identidade $\mathrm{BB}$, relatos de manifestações etc. $\mathrm{O}$ cenário político em que eles atuam aponta para a emergência da compreensão de novas dinâmicas de atuação de movimentos sociais e de ativismo, que se utilizam das redes digitais.

Entre as práticas e apropriações sociais da internet atualmente, o Facebook e outros sites de redes sociais são os mais utilizados no mundo. A ação de compartilhamento no Facebook ou a replicação de mensagens no Twitter, por exemplo, revelam um alargamento nas relações de contato, partilha ou interação entre os usuários, independente dos mesmos pertencerem a uma mesma rede social. ${ }^{24}$

Para alguns, os atos praticados pelos Black Blocs representavam apenas desordem, frente à violência e táticas utilizadas, contudo, vamos analisar o quanto posto por Esther Solano:

\footnotetext{
${ }^{23}$ BEZERRA, Arthur Coelho; GRILLO, Carolina Christoph. Batalha nas ruas, guerra nas redes: notas sobre a cobertura midiática da violência em manifestações. Liinc em Revista. Rio de Janeiro, v. 10, n. 1, p. 195 - 210, maio 2014. p. 200.

${ }^{24}$ CARREIRO, Rodrigo. Black Bloc em ação: reforço de identidade e outras dinâmicas de ativismo no Facebook. Liinc em Revista, v. 10, n. 1, 2014, p. 63.
} 


\begin{abstract}
Às vezes os enfretamentos sociais são enfrentamentos semióticos, de categorias e símbolos. Afinal, quem tem o poder de definir é sempre que impõe sua visão das coisas. A linguagem sempre é uma opção política.

Lembro-me da manifestação de 14 de setembro de 2013. Estávamos passando pela avenida Paulista, quando um dos adeptos do Black Bloc, com tom bastante severo, fez uma interpelação direta a um grupo de pessoas. Elas estavam sentadas num bar, olhando para rua, distraídas, leves, fotografando o protesto para, com grande possibilidade, colocar as imagens minutos depois na timeline do seu Facebook, continuando esse neurótico teatro cotidiano.

Não nos vão acusar de rebeldes sem causa. Temos uma causa...

Por que vocês se acomodam? Você que têm dinheiro, por que ficam aí? Seu silêncio é vandalismo. É que vocês vivem num mundo diferente? Parece que vocês estão vendo uma realidade diferente e não enxergam o que está acontecendo. ${ }^{25}$
\end{abstract}

Conforme elucidado no item 1.3.2 (Desordem: ausência de ordem ou ordem em outra perspectiva), a des"ordem" é na verdade uma ordem em outra perspectiva, onde o

des"ordeiro", busca tão somente convalidar seu ponto de vista sobre determinada "ordem", previamente estabelecida por/para conveniência de quem a constituiu, sendo imputado a quem pensa contrariamente o "título" de desordeiro, quando na verdade, apenas, expõe sua forma de pensar em disparidade com a do outro.

Ou seja, pactuamos do entendimento de que as convocações de manifestações pelas redes sociais representam uma nova forma de participação política e a busca pela efetividade da democracia.

Igualmente, conforme bem relatou Esther Solano, defendem uma causa, que eles acreditam ser a correta. Importa frisar que não concordamos com as táticas e o aparelhamento utilizado pelos adeptos do Black Bloc, no entanto, não podemos negar que eles também utilizam as redes sociais para, de alguma forma, efetivar a democracia, ao passo que não os qualificamos como os propagadores da desordem, contudo, a ausência de um diálogo mais aprofundado, bem como a ausência estatal em diversos aspectos, motivou, motiva e motivará pessoas com pensamentos mais radicais, e esse é mais um gargalo a ser enfrentado, ou seja, ouvir os radicais, pois no processo democrático o "ouvir" desempenha papel tão importante quanto o manifestar.

\title{
8. O PROBLEMA DA EXCLUSÃO DIGITAL E NECESSIDADE DE IMPLEMENTO DE INSTRUMENTOS PARA EFETIVAÇÃO DOS DIREITOS DO E-CIDADÃO E DA CIBERDEMOCRACIA
}

A inclusão digital é fenômeno cultural (educacional) e não propriamente ligado ao aparelhamento por equipamentos e acessos físicos. Do contrário, a inclusão digital já seria uma realidade no Brasil, que detém mais celulares que o número de habitantes. ${ }^{26} \mathrm{~A}$ inclusão social, um ponto crucial, impacta nos fatores de inclusão digital.

Assim, entendemos que a inclusão digital somente atingirá a todos, por meio da educação e não apenas por meio da compra de computadores, da disponibilidade de espaços físicos, do acesso à internet, ou seja, não basta apenas fomentar instrumentos e o mero ingresso

\footnotetext{
${ }^{25}$ SOLANO, Esther. Mascarados: a verdadeira história dos adeptos da tática Black Bloc. São Paulo: Geração Editoral. 2014. p. 103.

${ }^{26}$ Precisamente 242,1 milhões de Telefones Celulares no Brasil em Jun/17, o que corresponde a densidade de celulares em 116,65 cel/100 hab. Fonte: Teleco - http://www.teleco.com.br/ncel.asp (Acesso em 10/08/2017).
} 


\section{REVOLUÇÃO TECNOLÓGICA, REDES SOCIAIS E DESAFIOS CONTEMPORÂNEOS PARA EFETIVAÇÃO DA CIBERDEMOCRACIA E DOS DIREITOS DO E-CIDADÃO: UMA PROPOSTA PARA REFERENDUM DE QUESTÕES POLÍTICAS IMPORTANTES}

nas escolas, é preciso possibilitar a permanência, esta é que garantirá, de fato, a paridade entres as pessoas.

Além do ingresso e permanência nas escolas, fato preponderante para a inclusão social, temos de efetivar mecanismos capazes de propiciar, também, a inclusão digital. Entendemos que a escola desenvolve papel importante na rede de relacionamentos que os jovens criam. Sabemos, também, que as novas tecnologias são banais para alguns, enquanto que, para outros, é apenas um sonho.

Assim, aqueles que não dispõem de conhecimento mínimo sobre a cibernética e não dispõem de acesso à rede mundial de computadores, às redes sociais, acabam sofrendo Cyberbullying ${ }^{27}$ (trata-se de violência praticada contra alguém por meio da internet, redes sociais).

Nesse diapasão, a conscientização é o melhor caminho a ser trilhado para a efetivação do e-cidadão e da ciberdemocracia, sendo a inclusão digital um balizador de oportunidades na contemporaneidade.

De tal modo, para promover maior acesso digital, cremos que o governo deve promover, como disciplina básica do ensino médio, instrumento curricular que viabilize o começo do fim da exclusão digital, ou seja, uma disciplina que aja como propulsor para amenizarmos/eliminarmos a exclusão digital.

Não obstante, segundo o que pensamos, a aprovação do PLS nº129/2010 (que propõe alterar a Lei n ${ }^{\circ} 9.709$, de 18 de novembro de 1998, para estabelecer a possibilidade de subscrição eletrônica para apresentação de projeto de lei de iniciativa popular), que atualmente se encontra na Câmara dos Deputados (PL 7005/2013) aguardando Parecer do Relator na Comissão de Constituição e Justiça e de Cidadania (CCJC), deve ser relatado, aprovado e sancionado, para, assim, caminharmos no sentido da efetivação dos direitos do ecidadão.

Com essas duas ferramentas, acreditamos que, aos poucos, romperemos algumas barreiras para a efetivação dos direitos do e-cidadão.

\section{CONCLUSÃO: A FAVOR DO REFERENDUM DIRETO PELA REDE MUNDIAL DE COMPUTADORES?}

Por fim, depois de tudo o que discutido, apresentamos um ensaio a favor do referendum direto pela rede mundial de computadores a ser acessado pelos brasileiros nos casos de importantes e relevantes questões políticas, desde que compatíveis com esse método de coleta e com o nível cultural dos cidadãos, observada a vedação para limitação de direitos de minorias e matérias que envolvam diplomacia internacional, dentre outras incompatibilidades similares.

$\mathrm{Na}$ Grécia Antiga, com deliberações diretas em praça pública pelos cidadãos sobre as questões relevantes do Estado, o modelo cunhado para o exercício da democracia recebia a

\footnotetext{
${ }^{27} \mathrm{Na}$ internet e no celular, mensagens com imagens e comentários depreciativos se alastram rapidamente e tornam o bullying ainda mais perverso. Como o espaço virtual é ilimitado, o poder de agressão se amplia e a vítima se sente acuada mesmo fora da escola. E o que é pior: muitas vezes, ela não sabe de quem se defender.

Nova Escolar Cyberbullying: violência virtual. Disponível em:

<http://novaescola.org.br/formacao/cyberbullying-violencia-virtual-bullying-agressao-humilhacao 567858.shtml>. Acesso em: 27 jun. 2016.
} 
crítica de que não era inclusiva, pois a maioria da população não se inseria no conceito de cidadão. Por sua vez, passados centenas de anos, na contemporaneidade, período em que vivemos, a democratização ampla do acesso às informações alterou as necessidades dos cidadãos em vários aspectos, em especial, a própria depuração do conceito de cidadão e, com a inclusão digital, a inserção do e-cidadão, propiciando, nesse particular, uma democratização nunca vista antes. Agora podemos melhorar e incluir a todos. É uma questão de política pública na direção da ciberdemocracia e efetivação do e-cidadão.

Então, se podemos votar quem vai ao paredão no Big Brother, designar hora e local para acontecimentos públicos com milhares de pessoas, podemos também decidir os nossos principais destinos políticos, sem intermediários. E a vantagem da informatização vai além, pois envolve menos custos, por óbvio, do que a velha forma de referendum de votação no velho sistema eleitoral.

Todavia, essa solução deve ser dada em harmonia com a legislação, preservando os direitos das minorias, não sendo simplesmente a prevalência da vontade da maioria um exercício democrático. Deve-se levar em conta que o homem médio desconhece as leis, seu alcance e do sistema constitucional. Então há necessidade de ser informada a população, em determinadas matérias, sobre os pareceres da comissão de constituição e justiça, para que não haja desinformação e venha a ser aprovada regra prejudicial, facilmente verificada quando analisada com os elementos técnicos-legais. Por fim, deve se levar em conta questões sigilosas diplomáticas e no âmbito das relações exteriores, que não funcionam e não se encaixam perfeitamente em um sistema de informação ampla e de referendum.

Propõe-se, em conclusão, uma reflexão sobre um sistema informatizado para validar as principais decisões políticas, passando por referendum direto dos cidadãos, sem intermediários, ainda que se mantenha um sistema político-representativo.

\section{REFERÊNCIAS}

ALVES, Alaôr Caffé. Lógica: pensamento formal e argumentação: elementos para o discurso jurídico. 5 ed. São Paulo: Quartier latin, 2011.

ARISTÓTELES. Política. Brasília: Universidade de Brasília, 1985.

ARISTÓTELES. Política: os pensadores. São Paulo: Nova Cultura. 1999.

BARRETO, Fernando. Mobilização Social. In: BRAMBILLA, Ana (org.). Para entender

as mídias sociais. E-book, 2011. Disponível em: http://designices.com/wpcontent/uploads/2011/04/paraentenderas midiassociais.pdf $>$. Acesso em: 18 ago. 2016.

BEDONE, Rebeca. Em terra de whatsapp ligação é prova de amor. Disponível em: $<$ http://www.revistabula.com/5323-em-terra-de-whatsapp-ligacao-e-prova-de-amor/>. Acesso em: 11 mar. 2016.

BEZERRA, Arthur Coelho; GRILLO, Carolina Christoph. Batalha nas ruas, guerra nas redes: notas sobre a cobertura midiática da violência em manifestações. Liinc em Revista. Rio de Janeiro, v. 10, n. 1, p. 195 - 210, maio 2014. p. 200.

BOBBIO, Norberto. O futuro da democracia: uma defesa das regras do jogo. Rio de Janeiro: Paz e Terra, 1986.

BOBBIO, Norberto. Teoria geral da política: a filosofia política e as lições dos clássicos. Rio de Janeiro: Elieser, 2000.

BONAVIDES, Paulo. Ciência política. 16. ed. São Paulo: Malheiros, 2009. 


\section{REVOLUÇÃO TECNOLÓGICA, REDES SOCIAIS E DESAFIOS CONTEMPORÂNEOS PARA EFETIVAÇÃO DA CIBERDEMOCRACIA E DOS DIREITOS DO E-CIDADÃO: UMA PROPOSTA PARA REFERENDUM DE QUESTÕES POLÍTICAS IMPORTANTES}

BOYD, Danahet; ELLISON, Nicole. Social network sites: Definition, history, and scholarship. Califórnia, 2007. Disponível em: <http://jcmc.indiana.edu/vol13/issue1/ boyd.ellison.html>. Acesso em: 04 jun. 2013.

CARIBÉ, J. C. Classes Populares. In: BRAMBILLA, Ana (org.). Para entender as mídias sociais. E-book, 2011. http://designices.com/wpcontent/uploads/2011/04/paraentenderas midiassociais.pdf >. Acesso em: 18 ago. 2016.

CARREIRO, Rodrigo. Black Bloc em ação: reforço de identidade e outras dinâmicas de ativismo no Facebook. Liinc em Revista, v. 10, n. 1, 2014, p. 63.

CARVALHO NETO, Frederico da Costa. Novas Ferramentas e Privacidade. Florianópolis: FUNJAB, 2013. p. 233-249.

CASTELLS, Manuel; CARDOSO, Gustavo (Orgs.). A sociedade em rede: do conhecimento à ação política. Belém: Imprensa Nacional, 2005. p. 71.

COELHO, Fábio Ulhoa. Roteiro de lógica jurídica. 5.ed. São Paulo: Saraiva, 2004.

DE CICCO, Cláudio; GONZAGA, Álvaro de Azevedo. Teoria geral do Estado e ciência política. 7. ed. São Paulo: Revista dos Tribunais, 2016.

DONEDA, Danilo. Reflexões sobre proteção de dados pessoais em redes sociais. Revista Internacional de Protección de Datos Personales. n. 1. Dezembro 2012. Disponível em: $<$ http://habeasdatacolombia.uniandes.edu.co/wp-content/uploads/10_Danilo-Doneda_ FINAL.pdf $>$. Acesso em: 5 fev. 2014.

FERNANDES, Francisco. Dicionário Brasileiro Globo. 44.ed. São Paulo: Globo, 1996.

FERRI, Caroline. A (in) compreensão do paradoxo da soberania popular na democracia contemporânea. 2012. Tese (doutorado) - Universidade Federal de Santa Catarina, Florianópolis, 2012.

GADAMER, Hans Georg. Verdade e método II: complementos e índice. Rio de Janeiro: Vozes, 2002.

GONZAGA, Álvaro Luiz Travassos de Azevedo. O direito natural de Platão na República e sua positivação nas leis.2011. Tese (Doutorado em Direito) - Pontifícia Universidade Católica de São Paulo, São Paulo, 2011. p. 18. Disponível em: <https://sapientia.pucsp.br/bitstream/handle/ 5640/1/Alvaro\%20Luiz\%20Travassos\%20de\% 20Azevedo\%20Gonzaga.pdf>. Acesso em: 04 mar. 2017.

KELSEN, Hans. A democracia. 2.ed. São Paulo: Martins Fontes, 2000.

LIMA FILHO, Acácio Vaz de. O poder na antiguidade: aspectos históricos e jurídicos. São Paulo: Ícone, 1999.

LIMA, Sandra Lúcia Lopes. História da comunicação. São Paulo: Ebart, 1989.

LIPSON, Leslie. A civilização democrática. Rio de Janeiro: Zahar Editores, 1966.

LOCKE, John. Coleção os grandes filósofos do direito. São Paulo: Martins Fontes, 2002.

LOCKE, John. Segundo tratado sobre o governo. São Paulo: Martin Claret, 2011.

MAIN, Lucimara Aparecida; MORO, Maitê. Reputação da organização: gerenciamento de crise da imagem, como forma de garantir a função social e sustentabilidade financeira da empresa. Florianópolis: FUNJAB. 2014. p. 493-516.

MAQUIAVEL, Nicolau. O Príncipe. Ed. Ridendo Castigat Mores: São Paulo, publicação original em 1515, Tradutor: Nelson Jahr Garcia, 2002. Disponível em: <http://www.ebooksbrasil.org/ adobeebook/principe.pdf>. Acesso em: 04 mar. 2017.

MORIN, Edgar. Ciência com consciência. 8. ed. Rio de Janeiro: Bertrand Brasil, 2005.

PERELMAN, Chaim. Lógica jurídica: nova retórica. São Paulo: Martins Fontes, 2000. 
PIERRE, Martim. Dicionário Jurídico 2015: terminologia juridical e forense, brocados latinos. 7 ed. Niterói, RJ: Impetus, 2015.

RECUERO, R. Redes Sociais na Internet. Porto Alegre: Sulina, 2009. Disponível em: <http://www.ichca.ufal.br/graduacao/biblioteconomia/v1/recuero.pdf > Acesso em: 18 ago. 2016. p. 24.

RIOS, Aníbal Sierralta. A revolução tecnológica dos meios de comunicação e os desafios do direito e da democracia. Revista Meritum, v. 7, n. 1, p. 305-353, jan./jun. 2012 RODRIGUE, Joelza Ester. História em documento: imagem e texto. São Paulo: FTD, 2002.

ROQUE, Nathaly Campitelli. A ordem pública e seu regime jurídico do direito processual civil as questões de ordem pública. Revista dos Tribunais. vol. 908/ Jun. 2011.

SANTOS, José Erimar dos; SANTOS, Valmaria Lemos da Costa. Geografia dos protestos e meio comunicacional: redes sociais digitais e manifestações populares. Revista Movimentos Sociais e Dinâmicas Espaciais. Recife, v. 2, n. 2, 2013. Disponível em: <http://www.revista.ufpe. br/revistamseu/index.php/ revista/article/viewFile/50/92>. Acesso em: 18 ago. 2016.

SCHUMPETER, Joseph A. Capitalismo, socialismo e democracia. Rio de Janeiro: Fundo de Cultura, 1961.

SOLANO, Esther. Mascarados: a verdadeira história dos adeptos da tática Black Bloc. São Paulo: Geração Editoral. 2014. p. 103.

SOUZA Luciana Cristina de. Análise crítica da legitimidade do estado a partir da aplicação do princípio da resiliência. Direito, governança e novas tecnologias. CONPEDI/ UFMG/FUMEC/Dom Helder Câmara; Florianópolis: CONPEDI, 2015. Disponível em: <http://www.conpedi.org.br/publicacoes/66fsl345/81s48682/0cO30v9hDfn0KKv1.pdf>. Acesso em: 11 ago. 2016.

STEFFEN, César. Midiocracia: uma nova face das democracias contemporâneas. 2010. Tese (Doutorado em Comunicação Social) - Pontifícia Universidade Católica do Rio Grande do Sul, Porto Alegre, 2010.

TELLES Júnior, Goffredo. Iniciação na ciência do direito. 4. ed. São Paulo: Saraiva, 2008.

VIEGAS, Cláudia Mara de Almeida Rabelo; RABELO, Cesar Leandro de Almeida. A Participação da Sociedade Brasileira nas decisões do Governo a luz da Democracia Digital. Disponível em: <http://ambito-juridico.com.br/site/?artigo_id=10708\&n_link=revista_artigos _leitura>. Acesso em: 04 mar. 2017.

XAVIER, Maria Leonor. Questões de Filosofia na Idade Média. Lisboa: Colibri, 2007. 